Article

\title{
Cnaphalocrocis medinalis Moths Decide to Migrate when Suffering Nutrient Shortage on the First Day after Emergence
}

\author{
Jia-Wen Guo, Ping Li, Jie Zhang, Xiang-Dong Liu, Bao-Ping Zhai * $\mathbb{C D}^{\text {and }}$ Gao $\mathrm{Hu}$ * \\ Key Laboratory of Integrated Management of Crop Diseases and Pests (Ministry of Education), College of Plant \\ Protection, Nanjing Agricultural University, Nanjing 210095, China; 2016202022@njau.edu.cn (J.-W.G.); \\ 2017102102@njau.edu.cn (P.L.); 2014202037@njau.edu.cn (J.Z.); liuxd@njau.edu.cn (X.-D.L.) \\ * Correspondence: bpzhai@njau.edu.cn (B.-P.Z.); hugao@njau.edu.cn (G.H.); Tel.: +86-25-8439-6381 (G.H.)
}

Received: 8 September 2019; Accepted: 16 October 2019; Published: 20 October 2019

check for updates

\begin{abstract}
Migration is a costly strategy in terms of reproduction output. Competition for limited internal resources leads to physiological management of migration-reproduction trade-offs in energy allocation. Migratory insects must choose to determine to allocate energy into reproduction or migration when confronted insufficient energy supply. Although nutrient shortage is known to stimulate insect migration to escape deteriorating habitat, little is known about when and how migratory insects make decisions when confronted by a nutritional shortage. Here Cnaphalocrocis medinalis (Lepidoptera: Pyralidae), a migratory rice pest in eastern Asia, was used to study the effects of starvation on reproductive traits, behavioral traits and energy allocation. The result showed that one or two days' starvation before preoviposition did not significantly reduce the fertility (total egg per female laid) and flight capability (flight duration and distance) of both sexes $C$. medinalis. The preoviposition period was extended significantly only if moths were starved starting on the first day after emergence. Also, take-off percentage of moths starved since their first day increased significantly, and continued to increase even if supplemental nutrients were supplied as honey solution in later days. Moths starved on the first day appeared to allocate or transfer triglycerides into the thorax to maintain the migration process: the quantity of thoracic triglycerides did not differ with age, but abdominal triglycerides decreased with age if starvation continued. These results indicate that the first day post-emergence is a critical period for $C$. medinalis to decide to migrate or not in response to lack of food. This furthers our understanding of the population dynamics of migratory insects under natural conditions.
\end{abstract}

Keywords: adult starvation; energy trade-off; reproduction; migration; triglyceride

\section{Introduction}

Migration is an adaptive mechanism for insects to avoid adverse conditions and exploit temporary or patchy habitats [1,2]. In most insects, migration usually occurs in the pre-reproduction period [3], a phenomenon termed by Johnson [4] as "oogenesis-flight syndrome". Many insects exhibit this behavior, such as Myzus persicae [5], Aphis gossypii [6], and Gryllus firmus [7]. There is a trade-off between migration and reproduction in these insects. In other words, the greater the amount of energy consumed for flight, the less remains for development and reproduction. A longer preoviposition period, lower fertility, lower reproductive energy investment, higher take-off percentage and stronger flight capacity are usually associated with migratory behavior of insects [8-11].

Food conditions have important effects on the reproduction and migration of insects $[2,4,12,13]$. In addition to the quality and quantity of food intake, the time of nutrient intake plays an important 
role in determining reproductive and migration behavior [14-16]. In nature, a majority of adult insects, such as Lepidoptera, Diptera, and Hymenoptera species, need nutrient supplements to enhance reproduction [17-20]. Adult nutritional status affects the reproductive behavior of insects, including mating [21,22] and oviposition [23-25]. In addition, since migration of most insects usually occurs when the adult is sexually immature [3], the decision by adult to migrate may be more directly affected by nutrient conditions in the adult stage than in the larval stage. Previous studies have suggested that the supplementation of nutrition in the adult affects insect migratory behavior [2,4]. For example, the migratory movement of Danaus plexippus depends on availability of nectar resources [26], and large numbers of these butterflies are found at locations where nectar is abundant during migration season [27]. Lack of supplemental nutrition in adults can promote insect migration, as demonstrated in Bruchophagus roddi [28], Oncopeltus fasciatus [29] and Dysdercus cingulatus [30]. However, little is known about how newly emerged migratory insects make decisions on allocating resources towards reproduction and migration when faced with nutritional deficiencies.

Cnaphalocrocis medinalis (Lepidoptera: Pyralidae) is an important long-distance migratory pest, that has had serious outbreaks in many Asian countries in recent decades, especially in China [31,32]. It cannot overwinter in temperate climates. In China, only a few individuals can survive during winter in areas of Southern Yunnan, Southern Guangxi, Southern Guangdong and Hainan [31-33]. Instead, infestations in temperate zones are initiated by windborne spring/summer migrants from the southern areas. A northward migration begins in March every year, and migrant progeny further expand population distributions to cover the rice-growing regions in China, Japan and the Korean Peninsula [31-34]. From September onwards, the general direction of C. medinalis becomes predominantly south bound [31-34].

Like most nocturnal migratory moths, C. medinalis perform 'multi-stop' migration in 3-5 consecutive nights, in which moths only take off at dusk, terminate migratory flight the following dawn, and then take-off again at the next dusk [33]. Adult C. medinalis exhibit "oogenesis-flight syndrome" during migration, which means migration occurs during the immature stage of reproductive development [33-37]. Therefore, the migratory C. medinalis generally has a long reproductive preparation stage (longer preoviposition period, lower mating percentage and less fecundity for female) and a strong migratory propensity (higher take-off percentage and strong flight capability in both sexes) [12,34-37] than a non-migratory moth. C. medinalis migrants also reserve sufficient energy for migration [35,36]. Lipids, stored primarily as triglycerides, are the main energy sources for migration in many nocturnal moths [9], and C. medinalis migrants have more lipids stored in thorax than residents $[35,36]$. After one or two days post-emergence, $C$. medinalis needs to acquire supplemental nutrients, which are often sucked from plant flowers in the field such as Paspalum conjugatum, Amaranthus viridis, Ligustrum lucidum, and Gossypium spp. [12]. Nutritional supplementation in the adult stage is especially important for $C$. medinalis. Lack of supplementary nutrition prolongs the preoviposition period, and has a significant negative impact on reproduction and longevity [12]. The level of ovarian development of $C$. medinalis adults fed only water is significantly lower than that of females provided supplementary nutrition [38]. However, these studies were restricted to the effect of continuous starvation on reproduction in adult $C$. medinalis. The effects of starvation at different ages and for different durations on reproduction and migratory propensity are still unclear. Most studies have used only the durations of preoviposition period to indirectly reflect migratory propensity, but little is known about effects of adult nutrition or starvation in the adult stage on take-off behavior, flight capability and energy reserve and transfer. This raises important questions about the effects of adult nutrition on the migration and reproduction of newly emerged C. medinalis: (1) Does starvation at different ages and for different durations have different effects on female reproduction? (2) Does C. medinalis (both female and male) have a critical period of response to starvation? If yes, how does starvation during this period affect reproduction and migration decisions? (3) How does adult nutrition affect energy distribution in both female and male moths? 
To address these questions, we designed four independent experiments based on ecological and physiological aspects to study the effects of starvation of different durations or different timing (starvation at different starting ages) on the reproductive parameters (female only), migratory parameters and energy allocation of newly emerged C. medinalis and to identify the stage at which adult insects are sensitive to a lack of nectar. The results will help us understand the relationships between supplemental nutrients, migratory behavior and reproduction and elucidate the role of nectar resources in insect migration.

\section{Materials and Methods}

\subsection{Insects}

The larvae of $C$. medinalis were originally collected from rice fields in Nanjing, China. Larvae were reared on wheat seedlings until pupation [39]. Pupae were removed from the seedlings and transferred into a transparent plastic box (16 cm length, $24 \mathrm{~cm}$ width and $22 \mathrm{~cm}$ height), the bottom of which was filled with moist cotton wool to maintain high relative humidity. Pairs of newly emerged male and female adults were transferred to 500-mL transparent cups with absorbent cotton wool soaked in $5 \%$ honey solution as a supplemental nutrient. The cups were covered with plastic film, and the adults oviposited on the film. All the insects were reared in RXZ intelligent artificial climate chambers (Ningbo Jiangnan Instrument Factory, China) at $26 \pm 0.5{ }^{\circ} \mathrm{C}$ and $80 \%-90 \%$ relative humidity (RH) with a photoperiod of 14L:10D [39]. These insects were maintained for twenty generations in the laboratory when the experiments started.

\subsection{Adult Starvation}

To explore the effects of supplemental nutrition on the reproductive and migratory ability of C. medinalis and to identify the sensitive period of adult response to starvation, we starved adults at different ages and for different durations. We had three treatment groups: (1) no starvation, (2) early starvation treatments and (3) no feeding (Scheme 1). Among them, the early treatment feeding group included six treatment subgroups based on different day-age durations (one, two and three days) and different starting ages (one-, two- and three-day-old). Treatments were imposed identically on male and female moths.

\begin{tabular}{|c|c|c|c|c|c|c|}
\hline Treatment & Treatment & Adult age at start of & & Adu & day & \\
\hline group & duration & starvation (day) & 1 & 2 & 3 & $>3$ \\
\hline No starvation & Adult life & 1 & & & & \\
\hline \multirow{6}{*}{ Starvation } & \multirow{3}{*}{ One day } & 1 & & & & \\
\hline & & 2 & & & & \\
\hline & & 3 & & & & \\
\hline & \multirow{2}{*}{ Two days } & 1 & & & & \\
\hline & & 2 & & & & \\
\hline & Three days & 1 & & & & \\
\hline No feeding & Adult life & 1 & & & & \\
\hline
\end{tabular}

Black bars represent feeding with $5 \%$ honey solution and white bars represent feeding with water.

Scheme 1. Different treatment schemes of Cnaphalocrocis medinalis included in the study. 


\subsection{Reproductive Parameters of Female Moths}

Reproductive parameters, including mating percentage, total number of eggs per female and preoviposition period were measured in treated females. After adult emergence, each female was paired with a male and transferred to a 500-mL transparent cup set up as described above. The number of eggs per female was recorded daily to calculate the preoviposition period and fecundity. After death, the female moths were dissected, and the number of spermatophores was determined; female with spermatophores copulated successfully, and moths without spermatophores failed to copulate. The mating percentage of adult females in the starvation treatments and controls were computed. More than 14 adult females were examined for each treatment.

\subsection{Migration Parameters}

Migration parameters, including take-off behavior and flight capability, were used to indicate the migration propensity of adults. Because tests of reproductive characteristics obtained sensitivity to starvation at 1 day after emergence, three treatment groups were set up to test migration characteristics: no starvation group, first-day starvation group, and adult life-long starvation group. Radar observations and field trials have shown that C. medinalis adults take off at dusk, approximately 19:00 [31]; therefore, observation of take-off behavior and measurement of flight capability in one-, two-, and three-day-old adults started at 19:00.

\subsubsection{Percent Take-Off}

Adults for observation were transferred into 500-mL clear plastic cups. The cups were placed on white plastic foam (the take-off platform) and then covered with a transparent Polyvinyl chloride (PVC) cage (diameter $60 \mathrm{~cm}$, height $120 \mathrm{~cm}$ ) to observe the take-off behavior of the moths. Each time five female or male moths were observed, and at least 30 female or male moths were randomly selected for each treatment. An effective migratory take-off was defined as that moth took off and spiraled vertically with a vertical distance greater than $100 \mathrm{~cm}$. If moths kept still or just flew at lower height less than $100 \mathrm{~cm}$, the these moths were recorded as non-migratory [37]. Here, the number of adults that exhibited effective migratory take-off was recorded, and then take-off frequency was computed. All take-off experiments were started at dusk.

All take-off experiments were performed in a climate chamber $\left(26 \pm 1^{\circ} \mathrm{C}, 80 \%-90 \% \mathrm{RH}\right)$. All tested adults were moved into this climate chamber one hour before the observation of take-off behavior [37]. To simulate the lighting conditions of natural sunset, a light source composed of 20 rows of fluorescent lamps $(36 \mathrm{~V} / 40 \mathrm{~W})$ and 2 incandescent lamps $(12 \mathrm{~V} / 40 \mathrm{~W})$ was used. This light source was located $200 \mathrm{~cm}$ above the take-off platform to eliminate the effect of its heat on the internal temperature of the PVC cage. The light intensity was changed by gradually extinguishing 20 parallel fluorescent lamps ( 2 every $3 \mathrm{~min}$ ) and connecting the incandescent lamp with a potentiometer to create artificially simulated evening light. The indoor light intensity was gradually decreased from $1000 \mathrm{~L} \times$ to $0.1 \mathrm{~L} \times$ within $45 \mathrm{~min}$. The changes in light intensity during the observation period were simultaneously measured with a TES-1330A illuminometer.

\subsubsection{Flight Capability Measurement}

Flight tests of adults were conducted with a 24-channel computer-interfaced flight mill system (Jiaduo Science, Industry and Trade Co., Ltd., Hebi City, Henan Province, China) that automatically recorded total flight distance and flight duration. Each adult was tethered according to a technique described in previous studies [40-42]. Experimental moths were mildly anesthetized with ether before being glued onto a tether arm. The scales of the adults at the junction between the metathorax and abdomen were brushed off using a soft brush pen, and the metathorax of each adult was glued onto a hollow plastic tether (diameter of $0.80 \mathrm{~cm}$ and length of $1.5 \mathrm{~cm}$ ) with Pattex Superglue (Henkel Adhesive Co., Ltd., Guangdong, China). The flight capabilities of the adults were not affected by this 
treatment compared to those of the adults that were not anesthetized and glued to tethers [40-42]. The flight directions of the tethered moths remained perpendicular to the arm of the round-about flight mill. Light intensity was gradually reduced from $1000 \mathrm{~L} \times$ to $0.1 \mathrm{~L} \times$ to simulate natural dusk. Lights were turned off at 20:00 and turned on at 6:00 [37]. The flight environment was maintained at $26 \pm 1{ }^{\circ} \mathrm{C}$ and $80 \%-90 \% \mathrm{RH}$, and the flight test was carried out from 19:00 to 7:00. At least 22 female or male moths in each treatment were randomly selected to observe take-off behavior.

\subsection{Determination of Triglyceride Content}

The triglyceride content in the thorax and abdomen was measured when adults were starved on the first day after emergence, starved for the life of the adult, or fed honey throughout the adult period. After treatment, one-, two-, three-, four- and five-day-old adults were collected and maintained in liquid nitrogen for determination of triglyceride content using a Triglyceride Assay Kit (Nanjing Jiancheng Bioengineering Institute, Nanjing, China) according to the manufacturer's instructions. Each sample contained the thorax or abdomen of three moths, and at least 27 female moths or male moths in each treatment were used to determine triglyceride content. The thorax of each adult was separated from the abdomen after removal of the head, wings, and appendages. The weights of the thorax and abdomen were measured by an XP6 electronic balance $(0.001 \mathrm{mg}$, Mettler-Toledo AG, Sonnenberg Strasse, Schwerzenbach, Switzerland). A proportionate amount (M:V = 1:9) of PBS (0.1 M, pH 7.4) was added, and the mixture was homogenized in ice water. The sample was centrifuged at $587 \times g$ for $10 \mathrm{~min}$ at room temperature $\left(26 \pm 1{ }^{\circ} \mathrm{C}\right)$, and supernatant was used for triglyceride measurement. Measurement was performed for a blank tube with $7.5 \mu \mathrm{L}$ of distilled water, a standard tube with $7.5 \mu \mathrm{L}$ of reference material, and a sample tube with $7.5 \mu \mathrm{L}$ of sample homogenate. The OD value of $200 \mu \mathrm{L}$ of the solution was measured at $510 \mathrm{~nm}$ using a VersaMax microplate reader (Molecular Devices) after the addition of $750 \mu \mathrm{L}$ of working fluid. A portion of the sample supernatant was used to determine protein content using a Pierce ${ }^{\circledR}$ BCA Protein Assay Kit (Thermo Fisher Scientific Inc., Waltham, MA, USA). Finally, the triglyceride levels were determined using protein levels as a quantitative standard. The formula used was as follows:

Triglyceride content (mmol/gprot)

$=(\mathrm{OD}$ value of sample $-\mathrm{OD}$ value of blank $) /(\mathrm{OD}$ value of standard

- OD value of blank $\times$ calibrator content $(\mathrm{mmol} / \mathrm{L})$

$\div$ protein content of test $\times$ sample $($ gprot $/ \mathrm{L})$

where $\mathrm{mmol} / \mathrm{gprot}$ is millimol per gram of protein, $\mathrm{mmol} / \mathrm{L}$ is millimol per liter and gprot/L is grams of protein per liter.

\subsection{Data Analysis}

All data obtained from the studies are prented as the mean $\pm \mathrm{SE}$, except mating percentage and take-off percentage. The effects of adult starvation on the preoviposition period, total fecundity, triglyceride content and flight capability were analyzed by one-way ANOVA followed by Tukey's HSD tests. The reproduction traits were also analyzed using two-way ANOVA with duration and timing of starvation. Three-way ANOVA was used to analyze the effects of different treatment on flight duration, flight distance and triglyceride content in C. medinalis. Differences in mating percentage and take-off percentage among treatments were compared by the chi-square test. All statistical analyses were performed with R software (version 3.6, Microsoft Corporation, Redmond, WA, USA).

\section{Results}

\subsection{Influence of Adult Starvation on Reproduction}

The control group of $C$. medinalis females did not have a starvation experience in our experiment, and its mating percentage was $80.49 \%$ (33/41). In the group of starvation throughout adult life, only 
$16.07 \%(9 / 56)$ of females mated, and this mating percentage was significantly lower than that of the control group (Chi-square test: $\chi^{2}=14.09, p<0.001$; Figure 1a). In the groups of individuals starved for a short period (one, two or three days), mating percentages were 82.73\% (115/141), 79.07\% (34/43) and $71.43 \%(10 / 14)$, respectively. Compared with the control group, the result of Chi-square tests $\left(\chi^{2}=0\right.$, $p=1$ in all three comparisons; Figure 1a) indicated that a short period of starvation before oviposition did not significantly affect percentage of copulation in C. medinalis.
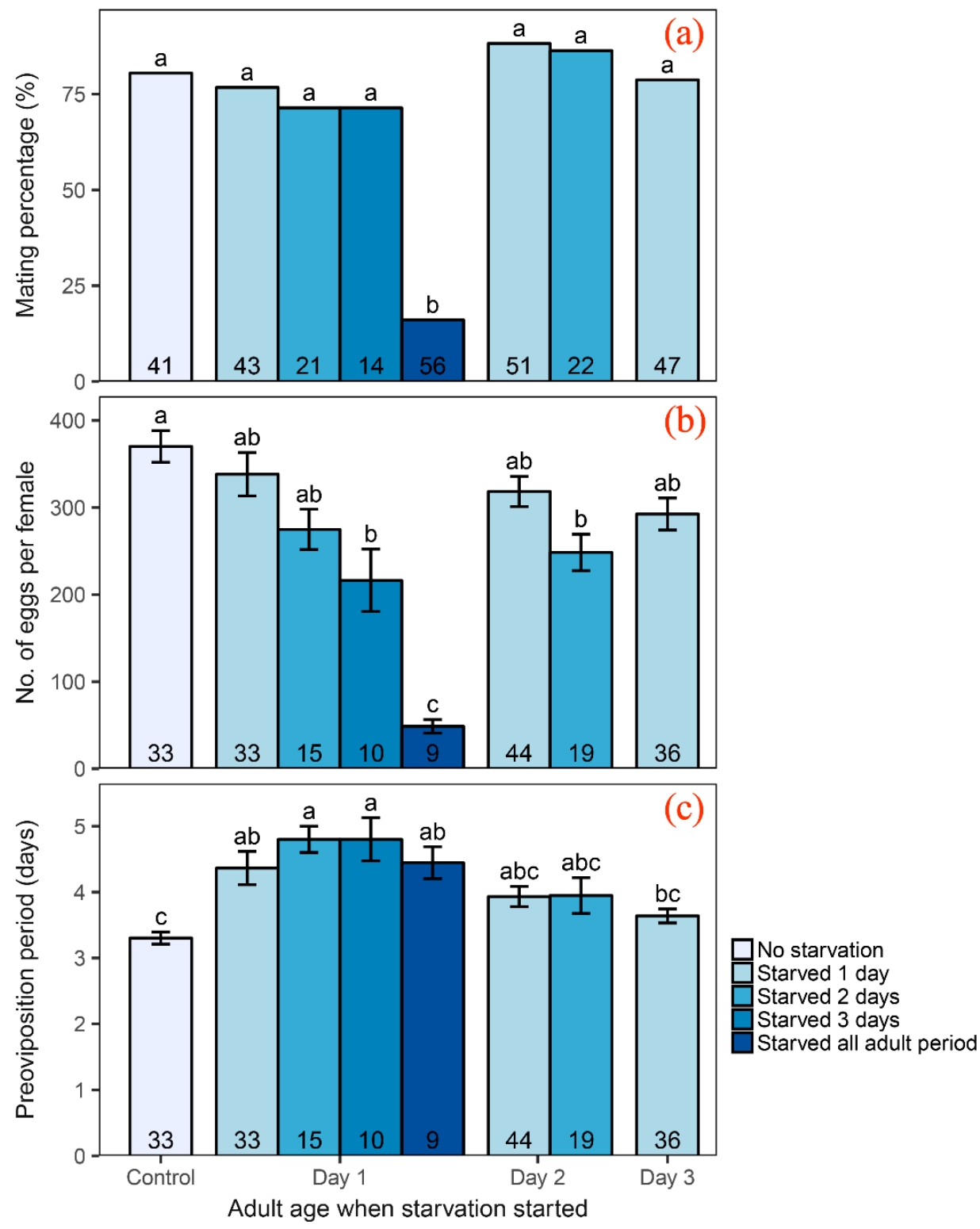

Figure 1. Mating percentage (a), fecundity (b) and preoviposition periods (c) of Cnaphalocrocis medinalis female after starvation. Different letters above the bars indicate significant differences between starvation durations $(p<0.05)$, based on the result of chi-square test for mating percentage and Tukey's HSD tests for fecundity and preoviposition periods. The numbers in the bars indicate sample sizes.

Starvation reduced female fecundity of $C$. medinalis, but the effect of starvation on the total number of eggs per female produced was found to be depended only on starvation duration, but not starvation timing (age of moth when starvation began) (Table 1, Figure 1b). The number of eggs per female decreased as starvation duration increased (Figure 1b). The female control group without starvation laid $370 \pm 18$ eggs $(n=33)$, while the group that starved throughout the whole adult life 
laid only $48.67 \pm 7.84$ eggs per female $(n=9)$ (Figure $1 b)$. However, one days' starvation (no. of eggs per female $=316 \pm 12, n=113$ ) or a starvation in their first two days after emergence (no. of eggs per female $=275 \pm 23, n=15$ ) did not significantly affect female fecundity compared with the control group (Figure 1b).

Table 1. Two-way ANOVA for the effects of duration and timing of starvation on fecundity and preoviposition period in female Cnaphalocrocis medinalis.

\begin{tabular}{llcccc}
\hline \multicolumn{1}{c}{ Trait } & \multicolumn{1}{c}{ Source } & df & $\begin{array}{c}\text { Mean-Square } \\
\text { Value (MS) }\end{array}$ & F-Values & $p$ \\
\hline \multirow{4}{*}{ Fecundity } & Starvation timing & 2 & 990 & 0.079 & 0.924 \\
& Starvation duration & 4 & 230,851 & 18.46 & $<\mathbf{0 . 0 0 1}$ \\
& Starvation timing $\times$ starvation duration & 1 & 257 & 0.02 & 0.89 \\
& Error & 191 & 12,508 & & \\
\hline \multirow{4}{*}{ Preoviposition period } & 2 & 3.28 & 3.43 & $\mathbf{0 . 0 3 5}$ \\
& Starvation timing & 4 & 8.86 & 9.26 & $<\mathbf{0 . 0 0 1}$ \\
& Starvation duration & 1 & 1.03 & 1.07 & 0.30 \\
& Starvation timing $\times$ starvation duration & 191 & 0.96 & & \\
\hline & Error & &
\end{tabular}

Starvation extended the preoviposition period of C. medinalis (Figure 1c, Table 1), but was affected by the starvation timing not the starvation duration (Table 1). Adults suffering starvation from the first day after emergence exhibited a significantly longer preoviposition period $(4.54 \pm 0.14$ days, $n=67)$ than the control group ( $3.3 \pm 0.09$ days, $n=33$ ) (Figure $1 c)$. In the groups of adults starved from age 2 or 3 days, their preoviposition periods (2-day-old group: $3.9 \pm 0.13$ days, $n=63$; 3 -day-old group: $3.6 \pm 0.11$ days, $n=36$ ) were not significantly different from that of the control group (Figure 1c).

Taking the above results together, we found that starvation had a negative effect on female C. medinalis reproduction, but a short period of starvation before oviposition did not significantly reduced the mating percent (Figure 1a) or the number of eggs per female (Figure 1b). The preoviposition period was extended significantly if moth suffered starvation in the first day after emergence (Figure 1c).

\subsection{Influence of Adult Starvation on Flight Performance}

Starvation was expected to stimulate C. medinalis adults to take off and start the migration process, as the preovipostion period was extended under starvation in our experiment (see previous section). As expected, the groups with a starvation experience had a higher take-off percentage, regardless of sex (Table 2, Figure 2a,b). In the control group without starvation experience, only 9.40\% (17/180) individuals took off in the first 3 days after emergence (Table 2, Figure 2b,c). All groups experiencing starvation at the age of 1 day had a low take-off percentage, only 14.29\% (20/140), which was similar to the control group (Chi-square test: $\chi^{2}=1.70, p=0.19$ ). This indicated that most $C$. medinalis moths did not commence their migration immediately after emergence. The takeoff percentages in the groups starved on day 1 increased from the second day of age (Figure 1b,c). The group starved for the first three days of adult life had a strong migratory propensity at 2- and 3-days old (takeoff percentage at day 2: $67.14 \%$ (47/70); day 3: $92.86 \%$ (65/75)). In the group starved on day 1 , takeoff percentages were $31.43 \%$ (22/70) o the second day, and 48.57\% (34/70) on the third day. These takeoff percentages were higher than that of control group (Chi-square test, day $2: \chi^{2}=5.94, p=0.015$; day $3: \chi^{2}=7.56, p=0.006$ ), but lower than that of the group starved for 3 days (Chi-square test, day $2: \chi^{2}=5.44, p=0.019$; day 3: $\chi^{2}=4.12, p=0.042$ ) (Figure 2a,b). Here, it should be emphasized that the takeoff percentage in the groups with one-day's starvation were higher at the age of 3 days than at the age of 2 days (Chi-square test: $\left.\chi^{2}=37.47, p<0.001\right)$. This result indicates that feeding after starvation did not reduce migration propensity even if the decision to migrate was initiated by starvation. 
Table 2. Three-way ANOVA for the effects of different treatments on take-off percentage, flight duration and flight distance in Cnaphalocrocis medinalis.

\begin{tabular}{|c|c|c|c|c|c|}
\hline Trait & Source & df & MS & F-Values & $p$ \\
\hline \multirow{8}{*}{$\begin{array}{l}\text { Take-off } \\
\text { percentage }\end{array}$} & Adult age & 2 & $16,891.56$ & 46.52 & $<0.001$ \\
\hline & Sex & 1 & 154.47 & 0.43 & 0.516 \\
\hline & Treatment & 2 & $23,182.94$ & 63.844 & $<0.001$ \\
\hline & Adult age $\times$ Sex & 2 & 190.81 & 0.53 & 0.593 \\
\hline & Sex $\times$ Treatment & 2 & 95.32 & 0.26 & 0.770 \\
\hline & Adult age $\times$ Treatment & 4 & 4294.37 & 11.83 & $<0.001$ \\
\hline & Adult age $\times$ Sex $\times$ Treatment & 4 & 181.98 & 0.50 & 0.735 \\
\hline & Error & 102 & 363.12 & & \\
\hline \multirow{8}{*}{ Flight duration } & Sex & 2 & 58.34 & 6.34 & 0.002 \\
\hline & Adult age & 1 & 85.54 & 9.30 & 0.002 \\
\hline & Treatment & 2 & 94.98 & 10.33 & $<0.001$ \\
\hline & Adult age $\times$ Sex & 2 & 11.19 & 1.22 & 0.297 \\
\hline & Sex $\times$ Treatment & 2 & 8.54 & 0.93 & 0.396 \\
\hline & Adult age $\times$ Treatment & 4 & 45.88 & 4.99 & $<0.001$ \\
\hline & Adult age $\times$ Sex $\times$ Treatment & 4 & 1.98 & 0.22 & 0.930 \\
\hline & Error & 358 & 9.20 & & \\
\hline \multirow{8}{*}{ Flight distance } & Sex & 2 & 163.29 & 7.00 & $<0.001$ \\
\hline & Adult age & 1 & 216.76 & 9.29 & 0.002 \\
\hline & Treatment & 2 & 218.48 & 9.36 & $<0.001$ \\
\hline & Adult age $\times$ sex & 2 & 47.95 & 2.06 & 0.130 \\
\hline & Sex $\times$ Treatment & 2 & 21.22 & 0.91 & 0.404 \\
\hline & Adult age $\times$ Treatment & 4 & 103.10 & 4.42 & 0.002 \\
\hline & Adult age $\times$ Sex $\times$ Treatment & 4 & 6.66 & 0.29 & 0.887 \\
\hline & Error & 358 & 23.33 & & \\
\hline
\end{tabular}

" $\times$ " is an interactive token. Significant values $(p<0.05)$ are printed in bold.

In the control group of $C$. medinalis without starvation, a short preoviposition period and a low takeoff percentage indicated that it did not have a strong propensity to migrate (see previous sections), but it still had strong flight capability before oviposition (Figure $2 b, c)$. The result of ANOVA indicated that flight duration was significantly different between female and male individuals (F: $4.84 \pm 0.43 \mathrm{~h}$ $\left.(n=72) ; \mathrm{M}: 3.31 \pm 0.33 \mathrm{~h}(n=88) ; F_{1,156}=9.71, p=0.002\right)$, but just a marginally significant difference between individuals at different ages $\left(F_{2,156}=2.94, p=0.056\right)$ (Figure $\left.2 c, d\right)$. In the group starved for duration of adult life, the flight duration in the first 3 days after emergence was $2.08 \pm 0.24 \mathrm{~h}(n=78)$, and there was not significantly difference between female and male individuals $\left(F_{1,74}=1.16, p=0.29\right)$, or individuals at different ages $\left(F_{1,74}=1.18, p=0.31\right)$. Nonetheless, we found that the flight capability of this group decreased with age (but not significantly), while the flight capability of the control group increased (marginally significant). Consequently, the flight capabilities of these two groups were significantly different at age 3 days (Figure 2c,d). This result indicated that starvation reduced the flight capability. In the group of individuals with one-day's starvation at age 1 day, flight duration in the first 2 days was $2.30 \pm 0.29 \mathrm{~h}(n=84)$, regardless of $\operatorname{sex}\left(F_{1,74}=1.15, p=0.29\right)$ or age $\left(F_{1,81}=0.31\right.$, $p=0.58$ ). Also, this flight capability was similar to that of other two groups (i.e., control and adults starved for life) at the same age (Figure 2c,d). At an age of 3 days, the flight duration of this group after one-day's starvation increased to $5.70 \pm 0.52 \mathrm{~h}(n=54)$, and this was even longer than that of the control group at the same age (just below significant). The result of flight distance was just similar to that of flight duration (Figure 2e,f), so the details of flight distance are not shown here.

In summary, starvation stimulated C. medinalis to fly and begin migration. The takeoff percentage did not decrease even if supplemental nutrient was supplied by feeding with honey solution (Figure 2a,b). The flight capability remained at a nearly stable level at the first 3 days after emergence even under starvation. Supplemental nutrition enhanced their flight capability, especially in the individuals starved for 1 day (Figure 2c-f). Thus far, the results suggest that migratory moths allocate new energy to migration but not to reproduction. 

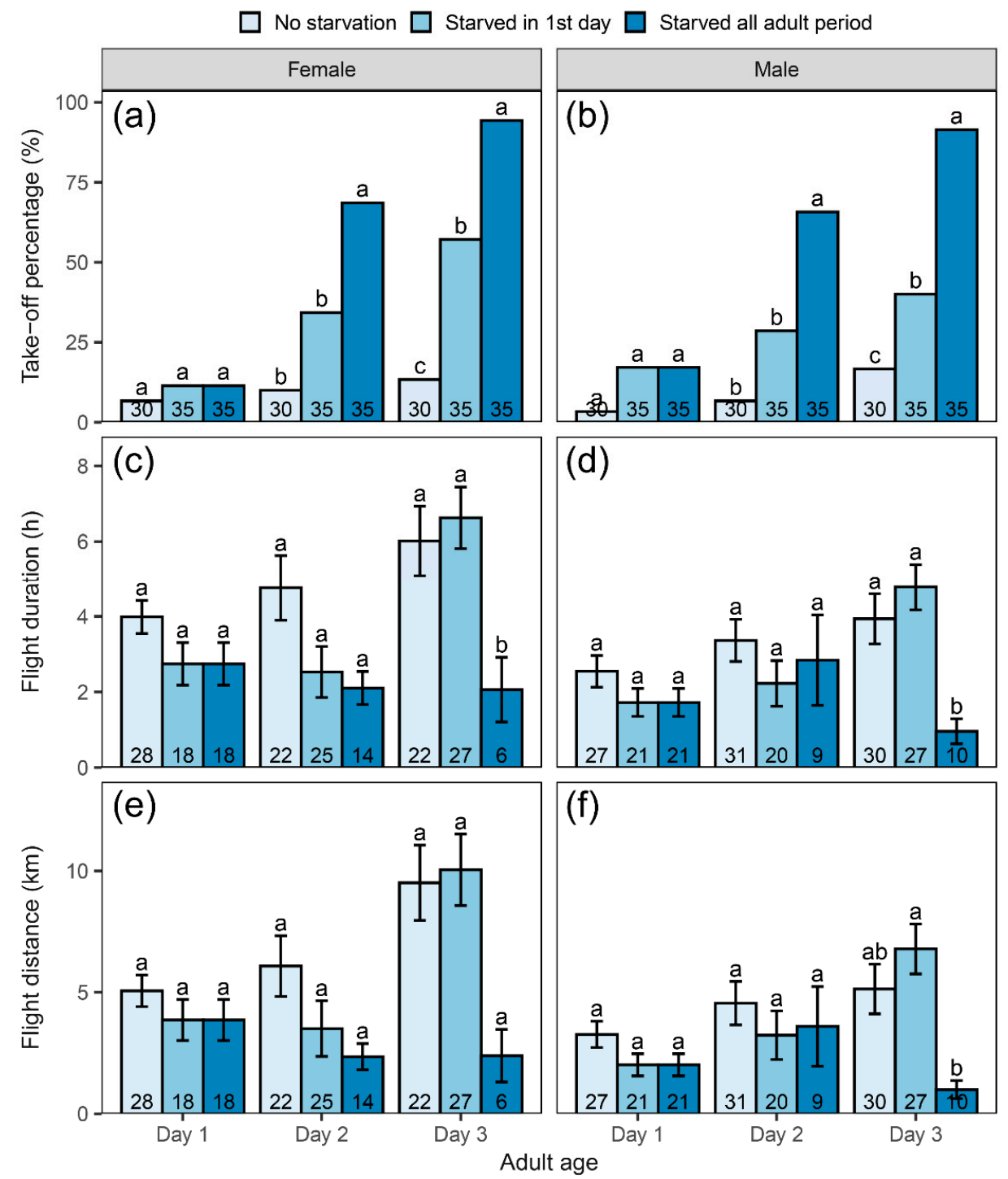

Figure 2. Flight responses of 1-3-day-old female and male adults after starvation. Different letters above the bars indicate significant differences between different treatments $(p<0.05)$, based on the result of chi-square test for take-off percentage and Tukey's HSD tests for flight duration and distance. The numbers in the bars indicate sample sizes. (a) The take-off percentage of female moths. (b) The take-off percentage of male moths. (c) The flight duration of female moths. (d) The flight duration of male moths. (e) The flight distance of female moths. (f) The flight distance of male moths.

\subsection{Influence of Adult Starvation on Triglyceride Content}

The triglyceride content in the thorax of $C$. medinalis was not significantly different among individuals of different sexes, ages or starvation treatments in our experiment (see more statistics detail in Table 3; Figure 3a,b), and was expected to help moths maintain a nearly stable flight capability during their first three days after emergence. However, the abdominal triglyceride content varied depending on treatment and an interaction effect between treatment and age (Table 3). In the control group, the abdominal triglyceride content increased with age, suggesting that moths allocate new energy to reproduction (Figure 3a,b). In the group starved throughout the whole adult period, the abdominal triglyceride content decreased significantly at age 3 days (Figure 3a,b). As flight capability did not decrease significantly and the triglyceride content in the thorax remained unchanged, it appeared that moths transferred energy from reproductive tissues to flight tissues to maintain migration capability. The group starved only on day 1 after emergence had a stable abdominal triglyceride content. 
Table 3. Three-way ANOVA for the effects of duration and timing of starvation on triglyceride content in the thorax and abdomen of Cnaphalocrocis medinalis.

\begin{tabular}{clcccc}
\hline \multicolumn{1}{c}{ Trait } & \multicolumn{1}{c}{ Source } & df & MS & F-Values & $p$ \\
\hline Thorax & Sex & 1 & 0.48 & 0.26 & 0.609 \\
& Adult age & 2 & 0.34 & 0.19 & 0.831 \\
& Treatment & 2 & 0.21 & 0.11 & 0.895 \\
& Adult age $\times$ Sex & 2 & 0.32 & 0.17 & 0.841 \\
& Sex $\times$ Treatment & 2 & 1.69 & 0.81 & 0.403 \\
& Adult age $\times$ Treatment & 4 & 2.19 & 1.18 & 0.319 \\
& Adult age $\times$ Sex $\times$ Treatment & 4 & 3.06 & 1.65 & 0.162 \\
& Error & 221 & 1.85 & & \\
\hline Abdomen & Sex & 1 & 12.46 & 3.05 & 0.082 \\
& Adult age & 2 & 6.71 & 1.64 & 0.196 \\
& Treatment & 2 & 39.45 & 9.67 & $<0.001$ \\
& Adult age $\times$ Sex & 2 & 1.36 & 0.33 & 0.718 \\
& Sex $\times$ Treatment & 2 & 5.72 & 1.40 & 0.248 \\
& Adult age $\times$ Treatment & 4 & 43.53 & 10.67 & $<0.001$ \\
& Adult age $\times$ Sex $\times$ Treatment & 4 & 0.62 & 0.15 & 0.962 \\
& Error & 221 & 4.08 & & \\
\hline
\end{tabular}

" $\times$ " is an interactive token. Significant values $(p<0.05)$ are printed in bold.

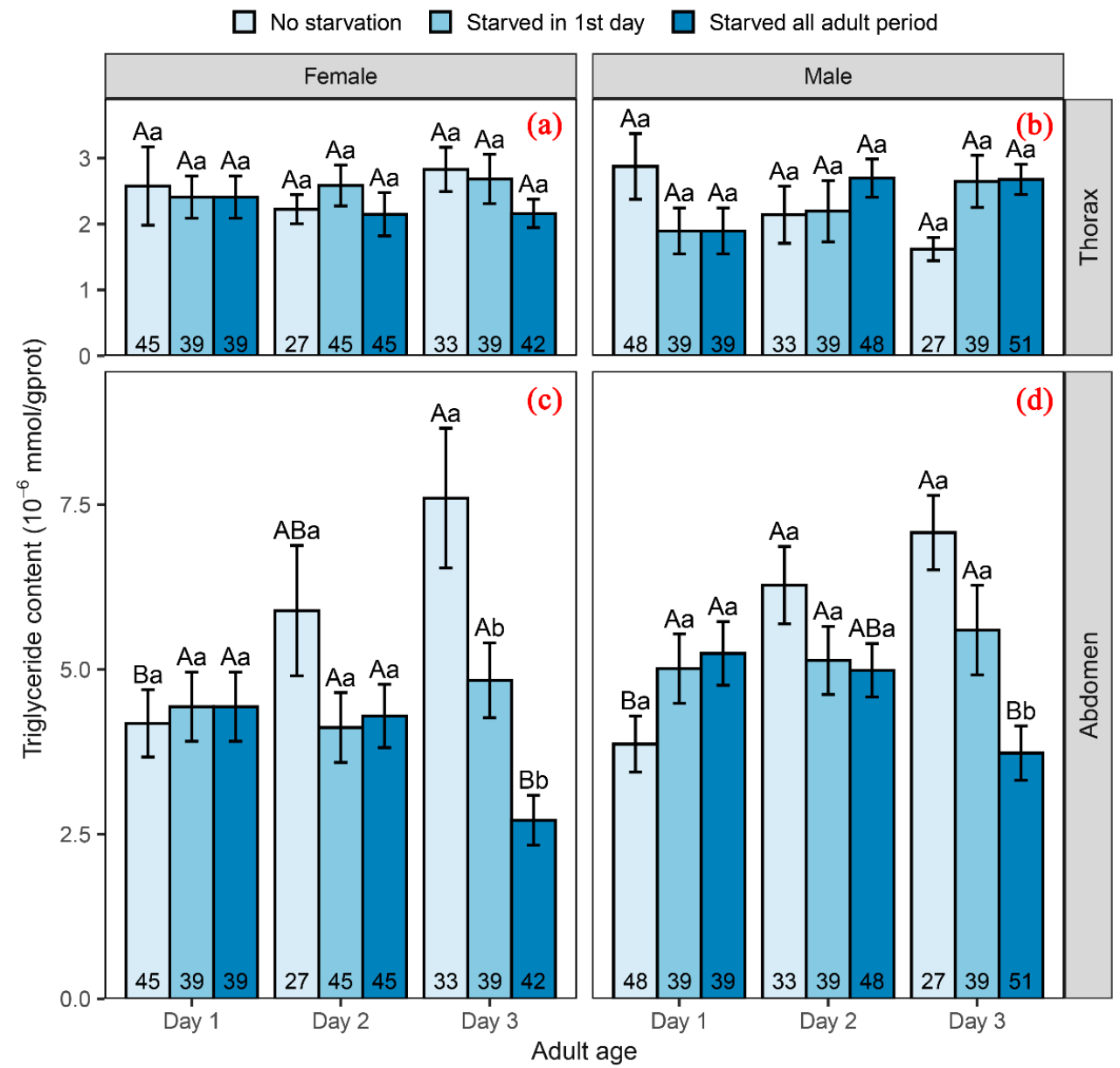

Figure 3. Triglyceride content of thorax in female (a) and male moths (b) and triglyceride content of abdomen in female (c) and male moths (d). Different uppercase letters indicate significant differences between different starvation treatments, and different lowercase letters indicate significant differences between different adult ages. The numbers in the bars indicate sample sizes. 


\section{Discussion}

\subsection{Effect of Adult Starvation on Reproductive Parameters}

C. medinalis moths have the ability to endure short-term starvation because of energy stored during the larval stage, but reproduction of the adult moths is strongly dependent on supplemental nutrition. Mating is costly for both sexes and increases energy expenditure [43]. Long-term starvation results in failure to mate adequately, which greatly affects the reproduction of insects. Many lepidopteran insects exhibit greatly reduced mating percentages, such as Spodoptera exigua [22] and Pseudaletia separata [21], when adult moths lack nutrition. In addition, even if adults successfully mate, females tend to reduce oviposition to adapt to starvation [44-46]. Most lepidopteran insects, such as Spodoptera exempta [47], and Athetis lepigone [48], show significant decline in fecundity when adults are undernourished. In this study, the fecundity of C. medinalis was noticeably reduced when starvation lasted for more than two days. Fecundity and ovarian development levels of $C$. medinalis females fed only with water were significantly lower than those of adults provided supplemental nutrition [12,38]. Therefore, adult nutrition is particularly important for reproduction and lack of nectar may strongly impact reproduction success in $C$. medinalis.

In general, to escape starvation, insects have evolved a series of strategies to deal with food shortages. These include physiological factors, such as reducing metabolic rate to save energy [49] to deal with starvation and behavioral responses, such as migration [1], to avoid starvation. As an insect with long-distance migration ability, C. medinalis can escape from bad environments and track resources by migration through time and space. In a previous study in southern China, it was found that $C$. medinalis emigrants (old instar larvae or pupae were collected from rice paddies during the emigration period of natural population and then fed indoor) had much lower fecundity (laid $84.76 \pm 59.74$ eggs per female) than residents ( $339.47 \pm 115.36$ eggs per female), but emigrants remained stronger migration propensity through days one to six after emergence [37]. By contrary, immigrants (completed its migration, moths collected from natural population during its immigration period and then fed indoor) laid the biggest number of eggs (400.50 \pm 70.07 eggs per female) [37,50]. It seems that migratory females reduce reproductive investment to support migration process until the termination of migration, and migrants allocate most resource to reproductive after migration and even had a higher fecundity than residents $[37,50]$. Therefore, we speculate that $C$. medinalis might need to reduce reproductive investment after short-term starvation in favor of allocating resources to searching for a more resource-rich environment.

\subsection{Effect of Adult Nutrition on Behavioral Response}

Adult starvation affects the timing of oviposition in C. medinalis, that is, the preoviposition period. Migration of $C$. medinalis begins while the adult is sexually immature, and ovarian development of females undertaking migration is slowed [32], resulting in longer preoviposition periods in migratory populations [37]. Therefore, prolongation of the preoviposition period is closely related to insect migration. Our results indicate that starvation significantly prolonged the preoviposition period of C. medinalis, which is consistent with the results of Zhang et al. [12]. In addition, there is a crucial stage in which some migratory insects respond to environmental factors, and during this crucial period, environmental changes can alter the direction of insect development, such as by inducing migration or reproduction [51-53]. Our study found an interesting phenomenon where starvation on the first day post-eclosion prolonged the preoviposition period. Other studies in C. medinalis also found that only the first-day adults suffering low temperature or treated by juvenile hormone shorten the preoviposition period $[41,54]$. Therefore, we believe that the first day after emergence is a critical period for $C$. medinalis to respond to environmental changes, and that starvation on that day promotes the onset of migration.

Our study showed that starvation in recently-emerged adults increased take-off percentage, and the longer the starvation duration, the higher the take-off percentage. Thus, adult starvation enhances 
propensity to migrate. Interestingly, the take-off percentage of $C$. medinalis subjected to restoration of nutrition after one day of starvation did not decrease but was significantly higher than that of the control group on the third day of adulthood, which indicated that starvation on the first day greatly enhanced migratory propensity. This result confirms that the first day after emergence is a critical period for C. medinalis to respond to environmental changes.

In our study, only starvation for more than two days decreased the flight capability. Such short-term starvation does not reduce flight capability in some insects but is exhibited by others, such as Pachnoda siuata [55] and Agrotis ipsilon [56]. Although the flight capability of $C$. medinalis measured by tethering flight mills did not show significant differences between adults in the short-term starvation groups and control, starvation might reduce the flight capability in some other non-migrating insects [57]. This may be due to the fact that $C$. medinalis deals with starvation differently from other migrating insects. The accumulation of energy during the larval period is limited, and when adults face starvation, energy may need to be redistributed from reproduction organs to flight organs, or reversely. As a migratory insect, $C$. medinalis are more inclined to allocate energy into flight organs to ensure that there is sufficient flight capacity to emigrate away from a food-poor environment, while other insects may reduce energy allocation to other organs to ensure reproduction. However, in other migrating insects such as Spodoptera exigua [58], starvation has been found to reduce flight capacity. This difference may be due to a difference in energy requirements between migratory insects. There was no significant change in flight capability in the case of days one to three after emergence of $C$. medinalis, but the flight capability of $S$. exigua increased with adult age [59]. When energy is limiting, $C$. medinalis can maintain flight capacity by redistributing triglyceride from the abdomen to thorax, but the flight of S. exigua requires more energy, and the storage of energy during larval stage is extremely limited [59]. However, the specific impact mechanism needs further research. Therefore, C. medinalis apparently has a strategy to allocate energy towards flight when it encounters a food shortage early in its adult life.

Lepidoptera adult behavioral strategies are directly or indirectly altered by changes in adult nutrition. Food shortage in newly emerged C. medinalis prolonged the preoviposition period, increased take-off propensity and maintained the long-distance flight capability. These behaviors showed a strong migratory propensity in C. medinalis and are consistent with our previous predictions, based on reproductive characteristics, that starvation induces migration.

\subsection{Effect of Adult Nutrition on Physiological Adjustment}

Our experiments clearly demonstrated that in the face of starvation, C. medinalis has prolongs reproduction development and increases migration propensity. Behavior results from complex physiological processes, and energy redistribution is one of the adaptive physiological countermeasures to food shortage. The transition between migration and reproduction results from the transformation or redistribution of intrinsic energy $[37,55]$. Because C. medinalis exhibits "oogenesis-flight syndrome" during its long-distance migration [33,34,50], there is a trade-off between flight and reproduction [9]. Moreover, triglycerides are the main energy sources for migration of $C$. medinalis $[9,35,36]$. Consequently, the triglyceride distribution in the thorax and abdomen reflects the transition between migration and reproduction. In this study, we found that, regardless of sex of the moth, its thoracic triglyceride content is not significantly reduced by starvation, indicating that $C$. medinalis maintains the energy supply to the thorax under hunger. In contrast, starvation affects the energy reserve in the abdomen. Our results show that when nutrition is supplemented, the triglyceride content of both female and male moths increases with the adult age, while adults who continue to be deprived have reduced triglycerides. However, moths starved on the first day did not quickly replenish their abdominal triglycerides after supplementing nutrition, which may be related to their prolonged preoviposition period and higher takeoff tendency on the third day after emergence. These results suggest that $C$. medinalis chooses between breeding and migration in response to nutritional deprivation. When food is abundant, C. medinalis choose to allocate more energy into breeding, while faced with starvation, it will allocate more energy into the flight-readiness. Somewhat surprisingly, although continuous starvation did not 
significantly reduce the triglyceride content of the thorax, the flight capability decreased on the third day after emergence. Since starvation can lead to a decrease in metabolic enzyme activity [55,60-62], we speculate that this may be related to the decline in activity of flight-related enzymes under starvation that affect energy efficiency, but the specific reasons are not clear and further research is needed to validate our speculation. In short, changes in physiological adjustment after starvation explained the results of reproductive characteristics and behavioral response. Starvation in the first day of C. medinalis life leads to the allocation of energy into their thorax, ensuring successful migration.

\section{Conclusions}

Overall, our study shows that a short starvation (one or two days) before preoviposition don't significantly reduce the fertility and flight capability of $C$. medinalis, and adult supplemental nutrition is essential for the reproduction of $C$. medinalis moths. One day after emergence is a critical period in the response to starvation. Starvation during the critical period promotes migratory traits and leads to migration in C. medinalis. Our results suggest that nectar resources play an important role in insect migration, and may be important for development of improved ecological control strategies.

Author Contributions: J.-W.G., G.H. and B.-P.Z. conceived and designed the experiments. J.-W.G., J.Z. and P.L. organized and performed the experiments. J.-W.G., X.-D.L. and G.H. analyzed and interpreted the data and wrote the paper. All authors read and approved the final manuscript.

Funding: This work was supported by the National Key Research and Development Program of China (2016YFD0300702) and the Fundamental Research Funds for the Central Universities (China) (KJJQ201803).

Acknowledgments: We thank Fa-Jun Chen from Nanjing Agricultural University for his advice and suggestions on experimental design. Thanks to Ye-Chen Wang, Jia-Hao Lu, Ming-Zhu Li and Ru-Jing Fan for their help in rearing $C$. medinalis.

Conflicts of Interest: The authors declare no conflicts of interest.

\section{References}

1. Chapman, J.W.; Reynolds, D.R.; Kenneth, W. Long-range seasonal migration in insects: Mechanisms, evolutionary drivers and ecological consequences. Ecol. Lett. 2015, 18, 287-302. [CrossRef]

2. Dingle, H. Migration: The Biology of Life on the Move, 2nd ed.; Oxford University Press: New York, NY, USA, 2014.

3. Kennedy, J.S. A turning point in the study of insect migration. Nature 1961, 189, 785-791. [CrossRef]

4. Johnson, C.G. Migration and Dispersal of Insects by Flight; Methuen: London, UK, 1969.

5. Zhang, X.X.; Wang, M.T. Study on the relationship between variation of ovary canal number and takeoff behaviour in green peach aphid. J. Plant Prot. 1991, 18, 161-166. [CrossRef]

6. Liu, X.D.; Zhai, B.P.; Zhang, X.X.; Xiong, F. The relationship between flight behavior and ovary development in the cotton aphid, Aphis gossypii. Entomol. Knowl. 2003, 40, 39-42.

7. Saglam, I.K.; Roff, D.A.; Fairbairn, D.J. Male sand crickets trade-off flight capability for reproductive potential. J. Evol. Biol. 2010, 21, 997-1004. [CrossRef] [PubMed]

8. Zera, A.J.; Denno, R.F. Physiology and ecology of dispersal polymorphism in insects. Annu. Rev. Entomol. 1997, 42, 207-230. [CrossRef] [PubMed]

9. Rankin, M.A.; Burchsted, J.C.A. The cost of migration in insects. Annu. Rev. Entomol. 1992, 37, 533-559. [CrossRef]

10. Shirai, Y. Flight activity, reproduction, and adult nutrition of the beet webworm, Spoladea recurvalis (Lepidoptera: Pyralidae). Appl. Entomol. Zool. 2006, 41, 405-414. [CrossRef]

11. Kent, J.W.; Rankin, M.A. Heritability and physiological correlates of migratory tendency in the grasshopper Melanoplus sanguinipes. Physiol. Entomol. 2010, 26, 371-380. [CrossRef]

12. Zhang, X.X.; Geng, J.G.; Lu, Z.Q.; Liu, W.J. The preliminary investigation of biological and ecological characteristics in Cnaphalocrocis medinalis. Entomol. Knowl. 1980, 17, 241-244.

13. Jiang, X.F.; Luo, L.Z.; Zhang, L.; Sappington, T.W.; Hu, Y. Regulation of migration in Mythimna separata (Walker) in China: A review integrating environmental, physiological, hormonal, genetic, and molecular factors. Environ. Entomol. 2011, 40, 516. [CrossRef] [PubMed] 
14. Boggs, C.L. Dynamics of reproductive allocation from juvenile and adult feeding: Radiotracer studies. Ecology 1997, 78, 192-202. [CrossRef]

15. Fischer, K.; Boggs, D.M.; O'BRIEN, D.M.; Boggs, C.L. Allocation of larval and adult resources to reproduction in a fruit-feeding butterfly. Funct. Ecol. 2004, 18, 656-663. [CrossRef]

16. Boggs, C.; Freeman, K. Larval food limitation in butterflies: Effects on adult resource allocation and fitness. Oecologia 2005, 144, 353-361. [CrossRef]

17. Heimpel, G.E.; Rosenheim, J.A.; Kattari, D. Adult feeding and lifetime reproductive success in the parasitoid Aphytis melinus. Entomol. Exp. Appl. 1997, 83, 305-315. [CrossRef]

18. Aluja, M.; Jacome, I.; Macias-Ordonez, R. Effect of adult nutrition on male sexual performance in four neotropical fruit fly species of the genus Anastrepha (Diptera: Tephritidae). J. Insect Behav. 2001, 14, 759-775. [CrossRef]

19. Bauerfeind, S.S.; Fischer, K. Effects of adult-derived carbohydrates, amino acids and micronutrients on female reproduction in a fruit-feeding butterfly. J. Insect Physiol. 2005, 51, 545-554. [CrossRef]

20. Harvey, J.A.; Cloutier, J.; Visser, B.; Ellers, J.; Wackers, F.L.; Gols, R. The effect of different dietary sugars and honey on longevity and fecundity in two hyperparasitoid wasps. J. Insect Physiol. 2012, 58, 816-823. [CrossRef]

21. Kanda, K. Feeding activity of adults of the oriental armyworm, Pseudaletia separata walker. Jpn. J. Appl. Entomol. Zool. 1987, 31, 297-304. [CrossRef]

22. Wang, H.S.; Xu, H.F.; Feng, C. Effect of adult foods on fecundity and ovary development of beet armyworm Spodoptera exigua (Hübner). Southwest China J. Agric. Sci. 2004, 17, 34-37.

23. Murphy, D.D.; Launer, A.E.; Ehrlich, P.R. The role of adult feeding in egg production and population dynamics of the checkerspot butterfly Euphydryas editha. Oecologia 1983, 56, 257-263. [CrossRef] [PubMed]

24. Miller, W.E. Spruce budworm (Lepidoptera: Tortricidae): Role of adult imbibing in reproduction. Environ. Entomol. 1987, 16, 1291-1295. [CrossRef]

25. Hong, F.; Martin, T.R.; Jaskowiak, K.M.; Hatle, J.D.; Whitman, D.W.; Borst, D.W. Starvation affects vitellogenin production but not vitellogenin mRNA levels in the lubber grasshopper, Romalea microptera. J. Insect Physiol. 2005, 51, 435-443. [CrossRef]

26. Rudolph, D.C.; Ely, C.A.; Schaefer, R.R.; Williamson, J.H.; Thill, R.E. Monarch (Danaus plexippus L. Nymphalidae) migration, nectar resources and fire regimes in the Ouachita Mountains of Arkansas. J. Lepid. Soc. 2006, 60, 165-170.

27. Brower, L.P.; Fink, L.S.; Walford, P. Fueling the fall migration of the monarch butterfly. Integr. Comp. Biol. 2006, 46, 1123-1142. [CrossRef]

28. Strong, F.E.; Bacon, O.G.; Russell, J.R. Flight habits of the alfalfa seed chalcid, Bruchophagus roddi Guss. (Hymenoptera: Eurytomidae). Hilgardia 1963, 35, 1-12. [CrossRef]

29. Dingle, H. Diapause in a migrant insect, the milkweed bug Oncopeltus fasciatus (Dallas) (Hemiptera: Lygaeidae). Oecologia 1974, 17, 1-10. [CrossRef]

30. Ahmad, I.; Khan, N.H. Effects of starvation on the longevity and fecundity of red cotton bug, Dysdercus cingulatus (Hemiptera: Pyrrhocoridae) in successive selected generations. Appl. Entomol. Zool. 1980, 15, 182-183. [CrossRef]

31. Riley, J.R.; Reynolds, D.R.; Smith, A.D.; Edwards, A.S.; Zhang, X.X.; Cheng, X.N. Observations of the autumn migration of the rice leaf roller, Cnaphalocrocis medinalis (Lepidoptera: Pyralidae) and other moths in eastern China. Bull. Entomol. Res. 1995, 85, 397-414. [CrossRef]

32. Zhang, X.X.; Geng, J.G.; Zhou, W.J. Studies on the migration of rice leaf roller, Cnaphalocrocis Medinalis Guenée. Acta Entomol. Sin. 1981, 23, 130-140.

33. Wang, F.Y.; Yang, F.; Lu, M.H.; Luo, S.Y.; Zhai, B.P.; Lim, K.S.; Mcinerney, C.E.; Hu, G. Determining the migration duration of rice leaf folder (Cnaphalocrocis medinalis (Guenée)) moths using a trajectory analytical approach. Sci. Rep. 2017, 7, 39853. [CrossRef] [PubMed]

34. Zhang, L.; Pan, P.; Sappington, T.W.; Lu, W.X.; Luo, L.Z.; Jiang, X.F. Accelerated and synchronized oviposition induced by flight of young females may intensify larval outbreaks of the rice leaf roller. PLoS ONE 2015, 10, e0121821. [CrossRef] [PubMed]

35. Zhang, X.X.; Zhou, W.J.; Geng, J.G.; Su, Q.L.; Zhu, Y.C.; Tang, J.Y. Studies on the energy source of flight and migration of the rice leaf roller (Cnaphalocrocis medinalis Guenée). J. Plant Prot. 1983, 10, 153-159. 
36. Zou, Y.D.; Chen, J.C.; Wang, S.H. Study on the relationship between the internal comtents of energy substance and the vitality of lipase with the migration of rice leaf roller (Cnaphalocrocis medinalis Guenée) and brown planthopper (Nilaparvata lugens Stål). Acta Ecol. Sin. 1983, 3, 55-70.

37. Yang, F.; Zheng, D.B.; Shi, J.J.; Gao, H.U.; Zhang, X.X.; Zhai, B.P. Observations on migratory behavior of Cnaphalocrocis medinalis: When will they take-off? Chin. J. Appl. Entomol. 2013, 50, 592-600.

38. Wu, J.C. Effect of changing photoperiod, temperature and food quality on the migration of rice leaf folder Cnaphalocrocis medinalis (Guenée). Acta Entomol. Sin. 1985, 28, 398-405.

39. Zhu, A.X.; Qiu, Q.; Liu, X.D. A method for rearing the rice leaf folder (Cnaphalocrocis medinalis) using wheat seedlings. Chin. J. Appl. Entomol. 2015, 52, 883-889.

40. Wang, F.Y.; Zhang, X.X.; Zhai, B.P. Flight and re-migration capacity of the rice leaf folder moth, Cnaphalocrocis medinalis (Guenée) (Lepidoptera:Crambidae). Acta Entomol. Sin. 2010, 53, 1265-1272.

41. Sun, B.B.; Jiang, X.F.; Zhang, L.; Stanley, D.W.; Luo, L.Z.; Long, W. Methoprene influences reproduction and flight capacity in adults of the rice leaf roller, Cnaphalocrocis medinalis (Guenée) (Lepidoptera: Pyralidae). Arch. Insect Biochem. Physiol. 2013, 82, 1-13. [CrossRef]

42. Huang, X.F.; Zhang, X.X.; Zhai, B.P. Effect of copulation on flight capacity and remigration capacity of Cnaphalocrocis medinalis (Guenèe). J. Nanjing Agricult. Univ. 2010, 33, 23-28. [CrossRef]

43. Himuro, C.; Fujisaki, K. Mating experience weakens starvation tolerance in the seed bug Togo hemipterus (Heteroptera: Lygaeidae). Physiol. Entomol. 2010, 35, 128-133. [CrossRef]

44. O'Brien, D.M.; Boggs, C.L.; Fogel, M.L. Making eggs from nectar: The role of life history and dietary carbon turnover in butterfly reproductive resource allocation. Oikos 2004, 105, 279-291. [CrossRef]

45. Kirk, K.L. Life-history responses to variable environments: Starvation and reproduction in planktonic rotifers. Ecology 1997, 78, 434-441. [CrossRef]

46. Juliano, S.A. Food limitation of reproduction and survival for populations of Brachinus (Coleoptera: Carabidae). Ecology 1986, 67, 1036-1045. [CrossRef]

47. Gunn, A.; Gatehouse, A.G. The effect of adult feeding on lipid and protein reserves in African armyworm, Spodoptera exempta, moths before and during reproduction. Physiol. Entomol. 1986, 11, 423-431. [CrossRef]

48. Jiang, X.F.; Rui, Y.; Lei, Z.; Cheng, Y.X.; Liu, Y.Q.; Luo, L.Z. Effects of supplementary nutrition on adult reproduction and longevity of Athetis lepigone (Möschler). J. Plant Prot. 2015, 42, 1004-1008.

49. Scharf, I. The multifaceted effects of starvation on arthropod behaviour. Anim. Behav. 2016, 119, 37-48. [CrossRef]

50. Zhang, X.X.; Lu, Z.Q.; Geng, J.G. Application of ovarian dissection of female Cnaphalocrocis medinalis moths in prediction and forecasting system. Entomol. Knowl. 1979, 16, 97-99.

51. Bertuso, A.G.; Morooka, S.; Tojo, S. Sensitive periods for wing development and precocious metamorphosis after precocene treatment of the brown planthopper, Nilaparvata lugens. J. Insect Physiol. 2002, 48, 221-229. [CrossRef]

52. Zhang, L.; Jiang, X.F.; Luo, L.Z. Determination of sensitive stage for switching migrant oriental armyworms into residents. Environ. Entomol. 2008, 37, 1389-1395. [CrossRef]

53. Duan, J.J.; Weber, D.C.; Dorn, S. Flight behavior of pre- and postdiapause apple blossom weevils in relation to ambient temperature. Entomol. Exp. Appl. 1998, 88, 97-99. [CrossRef]

54. Sun, B.B.; Zhang, L.; Jiang, X.F.; Luo, L.Z. Effects of temperature in adult period on the reproduction behavior of the rice leaf roller, Cnaphalocrocis medinalis (Guenée). Chin. J. Appl. Entomol. 2013, 50, 622-628.

55. Auerswald, L.; Gäde, G. Metabolic changes in the African fruit beetle, Pachnoda sinuata, during starvation. J. Insect Physiol. 2000, 46, 343-351. [CrossRef]

56. Sappington, T.W.; Showers, W.B. Reproductive maturity, mating status, and long-duration flight behavior of Agrotis ipsilon (Lepidoptera: Noctuidae) and the conceptual misuse of the Oogenesis-Flight Syndrome by Entomologists. Environ. Entomol. 1992, 21, 677-688. [CrossRef]

57. Kaufmann, C.; Collins, L.F.; Brown, M.R. Influence of age and nutritional status on flight performance of the Asian tiger mosquito Aedes albopictus (Diptera: Culicidae). Insects 2013, 4, 404-412. [CrossRef]

58. Jiang, X.F.; Luo, L.Z.; Hu, Y. The effect of compensatory nutrition condition on flight ability of beet armyworm Spodoptera exigua (Hübner). J. Plant Prot. 2000, 27, 327-332.

59. Li, K.B.; Gao, X.W.; Cao, Y.Z.; Luo, L.Z.; Jiang, X.F. Dynamics of energy reserves and utilization after tethered-flight in the beet armyworm, Spodoptera exigua (Hübner) (Lepidoptera: Noctuidae). J. Plant Prot. $2005,3,12-17$. 
60. Harshman, L.G.; Schmid, J.L. Evolution of starvation resistance in Drosophila melanogaster: Aspects of metabolism and counter-impact selection. Evolution 1998, 52, 1679-1685. [CrossRef]

61. Harshman, L.G.; Hoffmann, A.A.; Clark, A.G. Selection for starvation resistance in Drosophila melanogaster: Physiological correlates, enzyme activities and multiple stress responses. J. Evol. Biol. 1999, 12, 370-379. [CrossRef]

62. Marron, M.T.; Markow, T.A.; Kain, K.J.; Gibbs, A.G. Effects of starvation and desiccation on energy metabolism in desert and mesic Drosophila. J. Insect Physiol. 2003, 49, 261-270. [CrossRef]

(C) 2019 by the authors. Licensee MDPI, Basel, Switzerland. This article is an open access article distributed under the terms and conditions of the Creative Commons Attribution (CC BY) license (http://creativecommons.org/licenses/by/4.0/). 